\title{
La traducción funcional en los libros didácticos de español del PNDL 2012
}

\author{
Functional translation in spanish textbooks of PNDL 2012
}

\author{
Valdecy de Oliveira Pontes1 \\ Tatiana Xavier Silva2
}

\begin{abstract}
RESUMEN: El presente artículo es resultado del análisis de los libros didácticos de español del Plan Nacional del Libro Didáctico- PNLD 2012, propuesto por el Ministerio de Educación (MEC) en Brasil. El objetivo de este trabajo es analizar, bajo una perspectiva funcionalista, los ejercicios de traducción en los libros didácticos. Son respectivamente: El arte de leer -español, Enlaces-Español para jóvenes brasileños y Síntesis - Curso de lengua española. Para tanto, elaboramos un cuestionario que aporta preguntas sobre el abordaje de la traducción. Como marco teórico, utilizamos las contribuciones de Christiane Nord (1996, 2005, 2012), Katharina Reiss y Hans J. Vermeer (1996) de la corriente funcionalista de la traducción. A partir del análisis, concluimos que los libros didácticos, al utilizar la traducción como recurso didáctico para la enseñanza de lenguas, no se encuadran dentro de las sugerencias y orientaciones que propone la teoría funcional de la traducción, pues, al explotar tal recurso, no presentan informaciones de género, lugar, tiempo, funciones del texto base y meta, público receptor entre otros que están puestos en la guía de análisis, para realizar la actividad de traducción. Por fin, tras los resultados obtenidos, presentamos una reelaboración de las actividades, teniendo en cuenta la perspectiva funcional.
\end{abstract}

PALABRAS-CLAVE: Traducción funcional. Libro didáctico. Enseñanza de ELE. PNLD.

RESUMO: O presente artigo é resultado da análise de livros didáticos de espanhol do Plano Nacional do Livro Didático-PNLD 2012, do Ministério da Educação (MEC) do Brasil. O objetivo desse trabalho é analisar, sob o viés funcionalista, os exercícios de tradução nos livros didáticos. Os livros analizados são respectivamente: El arte de leer -español, Enlaces-Español para jóvenes brasileños y Síntesis - Curso de lengua española. Para tanto, foi elaborado um questionário com perguntas sobre a abordagem da tradução. Como referencial teórico deste trabalho, foram utilizadas as contribuições dos seguintes autores: Christiane Nord (1996, 2005, 2012), Katharina Reiss y Hans J. Vermeer (1996) da teoria funcionalista da tradução. A partir da análise, concluímos que os livros didáticos, ao utilizarem a tradução como recurso didático para o ensino de línguas, não

1 Professor doutor em Linguística (UFC) e com Pós-Doutorado em Estudos da Tradução (UFSC). Atualmente, é professor adjunto na graduação em Letras-Espanhol e no Programa de Pósgraduação em Linguística da Universidade Federal do Ceará (UFC). Fortaleza, Ceará, Brasil. Email: valdecy. pontes@ufc.br

2 Graduada em Letras-Espanhol - Universidade Federal do Ceará. 
se enquadram dentro da perspectiva funcional da tradução, pois não são considerados aspectos de gênero, lugar, tempo, função do texto base e meta, público receptor, dentre outros que estão listados na análise do trabalho. Após o resultado da análise das questões, apresentamos, com base na perspectiva funcional da tradução, propostas de recontextualização das atividades analisadas.

PALAVRAS-CHAVE: Tradução funcional. Livro didático. Ensino de ELE. PNLD.

ABSTRACT: The present article is the result of the analysis of Spanish textbooks of Plano Nacional do Livro Didático - PNLD 2012, Ministry of Education - MEC. The objective is to analyse, under the functionalist perspective, translation activities in the textbooks. The analysed textbooks were respectively: El arte de leer - español, EnlacesEspañol para jóvenes brasileños y Síntesis - Curso de lengua española. In order to do so, it was created a questionnaire with questions on the translation approach. As theoretical background, it was taken the contributions of the following scholars of the functionalist translation theory: Christiane Nord (1996, 2005, 2012), Katharina Reiss y Hans J. Vermeer (1996). From the analysis, we have concluded that the textbooks, by using translation as a didactic tool to the teaching of languages, do not fit into the functionalist perspective, since aspects such as genre, place, time, source and target text function, receiving public among others listed throughout the analysis. After the result of the analysis, we have presented, based upon the functionalist perspective of translation, proposals for the recontextualization of these activities.

KEYWORDS: Functionalist translation. Textbook. Teaching of SFL. PNLD.

\section{Introducción}

En los últimos años, las investigaciones en el campo de enseñanza y aprendizaje de lenguas extranjeras han crecido, eso porque, mediante el desarrollo tecnológico, se rompieron las barreras que impedían las relaciones interculturales. Actualmente, es fácil que un estudiante luso-hablante pueda comunicarse con nativos de países hispanohablantes, mediado por ordenador. Tal hecho impone que las editoriales de materiales didácticos intenten acompañar los cambios. Con eso, el libro, en lo que concierne a la concepción de lengua y su aprendizaje, pasa a ser un material vivo con la función no solo de llevar el conocimiento lingüístico, sino de contribuir en la formación del estudiante como sujeto.

Con respeto a los estudios en el área de enseñanza y aprendizaje de lengua extranjera, puede ser percibido como campo de investigación que tiene sus resultados muy poco aprovechados en la elaboración de materiales 
didácticos: la traducción. No obstante, bajo una perspectiva tradicional. Por otra parte, los actuales resultados de las investigaciones del campo de la traducción se plasman en un abordaje funcional de la lengua, que tratamos más adelante.

Teniendo en cuenta esta cuestión, nuestro trabajo evaluó tres colecciones de libros didácticos de español del PNLD 2012. Con el intuito de analizar las actividades de traducción, bajo la perspectiva de la traducción funcionalista de Nord (2012), Reiss y Vermeer (1996). Tras los resultados obtenidos, propusimos una reelaboración de las actividades de traducción. Se espera, con las propuestas, contribuir para la producción y elaboración del libro didáctico, además de presentar sugerencias de actividades que involucren la traducción, desde una perspectiva funcional. Para la fundamentación de este trabajo, utilizamos las contribuciones de la traducción funcional y los siguientes autores: Nord (1997, 2005, 2012), Reiss y Vermeer (1996), Tilio (2008), Santos (1999) y Laiño (2014).

\section{La traducción funcional en las clases de E/LE}

La teoría funcionalista, en lo que atañe al análisis textual, tiene como foco de sus atribuciones el destinatario del texto (address), ya sea el que lo recibe en su lengua materna o en lengua extranjera. Es lo que defiende Nord (1996) en sus investigaciones de traducción, tras las contribuciones de Reiss y Vemeer (1996). La primera lanza su mirada y justifica la funcionalidad de la traducción basándose en el texto originario, o sea, para que la traducción funcione el texto meta tiene que, según ella, ser equivalente al texto primario (original). Reiss participa del círculo de las ideas funcionalistas, pues, aunque se vuelva hacia el texto base, busca en él, en su sentido total, los elementos interculturales, factor que no pertenecía a las justificativas de los tradicionales, sus contemporáneos. Reiss, con su tipología textual, clasifica a los textos según su contenido en texto informativo, apelativo y expresivo. El objetivo de la autora era el de analizar el texto base: este es el punto de partida del abordaje funcionalista. Después de la proposición de la tipología textual de Reiss, tenemos la teoría del escopo de 
Vermeer (REISS; VEMEER, 1996), que valora el texto meta y lo planifica, a partir del escopo de la traducción (objetivo) y su público receptor.

Para Reiss y Vemeer (1996), lo que fundamenta una traducción no es la equivalencia entre texto original y texto meta, pues considera que el proceso de traducción se da en una situación determinada que involucra innúmeros factores y el principal de ellos es el skopo (objetivo, propósito) del encargo de la traducción. Así, propone en su teoría la noción de adecuación, pues, diferente de Reiss, para él, elementos culturales no son analizados solo en el texto originario, los de la lengua meta formarán parte del corpus del skopo, por lo tanto, la equivalencia se dará si tales factores culturales de la cultura originaria están presenten en la cultura meta. Es ahí que tal proceso se da entre culturas distintas. Para un claro resumen de las contribuciones de Vemeer, tenemos que la traducción es una información en una lengua y cultura meta de un texto de lengua y cultura originaria, y que, por lo tanto, tiene que ser coherente en sí mismo y con el texto originario.

Con base en las ideas de los dos expertos, Nord (2005) propuso el análisis del texto base antes del proceso traslativo. En las palabras de la autora (NORD, 2012, p. 9):

La necesidad de un adecuado análisis del texto base, antes de
comenzar a traducir o en la primera fase del proceso traductor, se ha
ido poniendo de relieve una y otra vez desde los años 1970. Los
primeros traductólogos alemanes (p.ej., Katharina Reiss ([1971] 2000,
2002), Wolfram Wilss ([1977]1982) o Werner Koller (1979), por
nombrar solo los más conocidos) están de acuerdo en que, sin tal
análisis, el traductor nunca podrá llegar a comprender todos los
aspectos del texto que tiene que traducir (de aquí en adelante: texto
base, TB).

Siendo el foco de la traducción funcional la comunicación de un texto en lengua y cultura meta, el receptor (address) ni siempre será nativo de la lengua meta. De ahí la importancia a la hora de conocer bien el texto a ser traducido y el cómo elegir los elementos que funcionarán para la lectura del texto meta. Hay un enlace a ese supuesto con la idea de lealtad del encargo de traducción, que, 
según la teórica, es ser leal a los elementos involucrados por dicho pedido, a saber: el emisor del texto de partida y sus intenciones; el iniciador del encargo traductorio y sus intenciones; los receptores de llegada y sus expectativas y conocimientos previos. Se nota un entendimiento amplio de armonía para mantener las relaciones entre los constituyentes del proceso traslativo a fin de un resultado único: la funcionalidad del texto traducido en la lengua/cultura meta.

Teniendo en cuenta esta cuestión, Nord (2012) plantea una lista de los elementos o funciones extratextuales, tales como: emisor, intención del emisor, receptor/destinatario, medio/canal, lugar, tiempo, motivo, función textual. Además de explicar detalladamente cómo analizar cada uno, ella expone la relación de interdependencia entre ellos; la cual muestra primero, su función independiente, y, luego, cómo esta se integra dentro del texto como un todo. En su modelo de análisis, para explotar los elementos aportados, la autora propone las siguientes cuestiones:

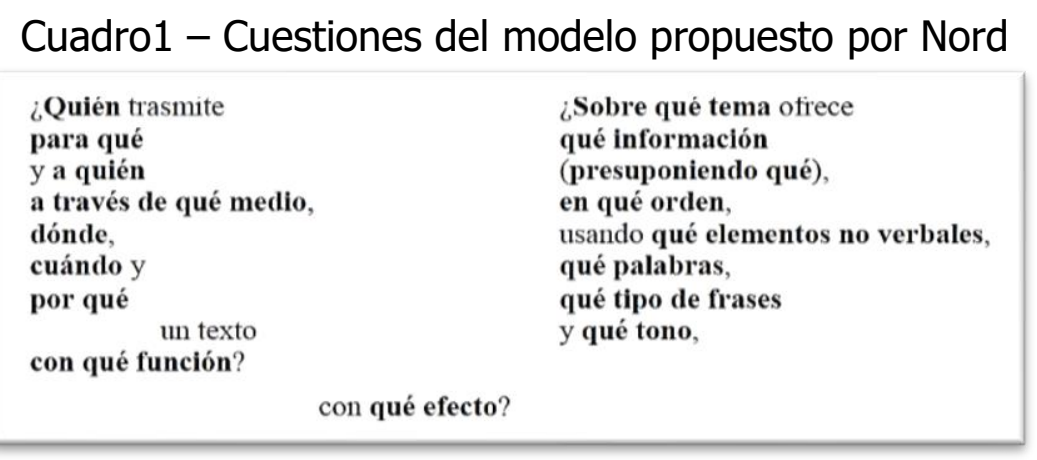

Fuente: Nord (2012, p. 42)

Este análisis es fundamental para la comprensión y enseñanza de cualquier idioma, ya que creará un acercamiento y contextualización del texto, de las culturas extranjera y materna. Las etapas para el análisis del modelo propuesto por Nord se basan en contestar sobre quién transmite el texto, para qué y a quién, por cuál medio, dónde, cuándo y por qué un texto (lugar, tiempo y motivo de la comunicación).

Es válido destacar que ni siempre el traductor tendrá estas informaciones en manos. Además, la importancia de los distintos aspectos dependerá del 
encargo de la traducción. Llevando eso para el contexto de enseñanza de lenguas, el profesor puede facilitar el análisis, y luego la traducción, disponiendo al alumno la mayor cantidad de informaciones posibles.

El alumno debe ser priorizado en este sentido. Así, los libros didácticos deben corresponder a la expectativa del lector. Entendemos que deba existir una interacción alumno/texto para que ocurra una aproximación de sentido por parte del alumno; el libro debe ofrecer soporte al alumno para que él pueda comprender un texto, una charla, actividades etcétera. Nicolaides y Fernandes (2008, p. 48) reflexionan sobre eso. Para ellas:

\begin{abstract}
Es preferible adoptar un material didáctico que no tiene exactamente un perfil adecuado a las necesidades y preferencias de los alumnos en cuestión y hacer una adaptación a lo largo del curso, que elaborar un material ineficaz, poco atractivo, que solo alcanza los objetivos el maestro o el sistema escolar y que no desarrollan el pensamiento crítico y reflexivo del alumno.
\end{abstract}

En ese momento, el profesor se enfrenta con la necesidad de promover un carácter funcional al libro didáctico, teniendo en cuenta su mayor foco: los estudiantes. Está claro que, para que ocurra una aproximación entre la LE y la lengua del alumno, no será suficiente la traducción gramatical de palabras aisladas o dentro del texto, aunque el objetivo sea el conocimiento lingüístico. Es de suma importancia conducir el alumno a lo cultural, expreso en el texto e ir más allá de él, con lo que se puede complementar de conocimiento acerca del contenido leído. Para la posibilidad de ese nivel cultural, es necesario que el alumno se encuentre inmerso en esta cultura para que tenga la oportunidad de obtener un conocimiento que ultrapase las barreras lingüísticas.

Para intentar hacer un análisis de la traducción en las clases de español, en nuestra perspectiva adoptada, es necesario primeramente hacer un análisis en los libros de idiomas, adoptados para enseñar lenguas. Tradicionalmente, estos libros traen ejercicios de vocabularios, en los que el enfoque es la traducción literal, o sea, palabra por palabra, sin considerar el contexto. En algunos manuales, encontramos listas de vocabularios, única ayuda de la cual 
dispone el alumno para enfrentarse con la traducción de cualquier tipo de texto. Estos materiales no explotan variaciones de tiempo, forma, función y cultura, conforme Laiño (2014), Millás (2012), Pontes y Francis (2014). Por ello, muchos problemas pueden ocurrir en el proceso de traducción de una lengua a otra, puesto que el libro didáctico desconsidera el valor estilístico y socio-histórico de la lengua base y de la lengua meta.

Teniendo en cuenta eso, es necesario un análisis profundo de los materiales que dispone el profesor para impartir sus clases, en este caso el libro didáctico-LD, que aún es la principal herramienta para la enseñanza de idiomas, tanto para el profesor como para los alumnos, conforme Coan y Pontes (2013). De esta manera, hace indispensable que la funcionalidad de la traducción ocurra dentro del libro didáctico de modo que posibilite al alumno su inserción en la cultura del otro.

En lo que concierne a la enseñanza de español en Brasil, la producción no se percibe de manera tan significativa por el lento proceso de implementación de la asignatura en los currículos escolares, sea en la primaria o en la secundaria. En lo que toca a su calidad, es notable el gran déficit cultural y lingüístico que se refleja en el alumnado, resultado muchas veces de una no adecuación del libro al público meta.

En el contexto de la enseñanza brasileña, muchos profesores acaban por apoyarse en el libro de tal forma que él pasa a ser la única herramienta que utiliza en sus clases. Santos (1999) expone que el libro didáctico es apuntado como el gran villano de la enseñanza en Brasil por su demasiada utilización en clase:

El libro didáctico [...] ha sido señalado como el gran villano de la enseñanza en Brasil, muchos educadores apuntan el libro didáctico como el gran obstáculo a impedir cambios significativos en las aulas. Algunos llegan a afirmar que debe ser simplemente retirado del alcance del profesor para que los cambios puedan ocurrir (SANTOS, 1999, p. $1) .^{3}$

\footnotetext{
${ }^{3} \mathrm{O}$ livro didático [...] tem sido apontado como o grande vilão do ensino no Brasil, muitos educadores apontam o livro didático como o grande obstáculo a impedir mudanças significativas nas salas de aula. Alguns chegam a afirmar que ele deve ser simplesmente retirado do alcance do professor para que as mudanças possam de fato ocorrer. (SANTOS, 1999, p. 1).
} 
De esta forma, es perceptible la necesidad de la creación de nuevas metodologías que puedan trabajar conjuntamente con el libro didáctico, ya que esta no es la única herramienta que dispone el profesor.

Por lo tanto, creemos que la traducción viene como un recurso didáctico que aún sigue siendo objeto de estudio, en el intento de comprobar su eficacia para la enseñanza de español como LE. De acuerdo con las investigaciones de Pontes y Francis (2014), Laiño (2014) y Pontes y Pereira (2016), es una estrategia que puede funcionar de una manera eficaz en las clases de español, cuando utilizada de forma adecuada, considerando el público meta.

El Ministerio de Educación brasileño evalúa la calidad con la que son producidos estos libros, y, a partir de estas evaluaciones, muchas mejorías ya han sido aportadas, de acuerdo con los diversos abordajes o métodos que están en vigor. No obstante, aún hay fallos y aspectos a mejorar.

En este artículo, analizamos las actividades de traducción de los libros didácticos, considerando que estos manuales deben ser producidos con base en la cultura del otro, o sea, del receptor, el producto final. De esa forma, no podemos desconsiderar que comprender un texto es acolchar la cultura del otro, es transcender culturalmente a través de palabras de la cultura de un pueblo.

\section{Procedimientos metodológicos}

Esta investigación se caracteriza como descriptiva de carácter cualitativo y tiene como finalidad analizar, bajo la perspectiva funcionalista, los ejercicios de traducción en los libros didácticos del PNLD 2012. La investigación descriptiva es presentada por Barros y Lehfeld (1990, p. 34) como "la descripción del objeto por medio de la observación y del levantamiento de datos ${ }^{4 . "}$

La convocatoria de libros didácticos del PNLD del último trienio (20162017), para la enseñanza secundaria, aprobó tres colecciones compuestas por tres ejemplares correspondientes a cada nivel; primero, segundo y tercero años,

\footnotetext{
${ }^{4}$ Traducción nuestra: "descrição do objeto por meio da observação e do levantamento de dados" (BARROS; LEHFELD, 1990, p. 34).
} 
periodo de uso de estos en la secundaria. El foco de nuestro análisis se dio en las actividades, para saber si ellas fueron elaboradas por medio de la traducción, específicamente en su aspecto funcional. Las colecciones analizadas fueron respectivamente: El arte de leer español, Enlaces - Español para jóvenes brasileños y Síntesis - Curso de lengua española.

Analizamos los libros didácticos llevando en consideración: (i) la concepción de traducción aportada por los teóricos funcionalistas; (ii) la proposición de un encargo didáctico, teniendo en cuenta la enseñanza de una LE (NORD, 2012); (iii) una tipología de textos auxiliares que puede servir de guía en el análisis del texto base y en la producción del texto meta en la práctica de la traducción pedagógica; (iv) los elementos intra y extratextuales del cuadro, propuestos por Nord (2005). Para tanto, levantamos algunas cuestiones divididas en tres ejes centrales con el objetivo de saber la naturaleza de la actividad y su objetivo final, para con eso reelaborarlas, bajo los conceptos de la corriente funcional. Cada eje está delimitado por preguntas, que tienen la intención de describir de manera clara los objetivos de las actividades.

\section{EJE -01- Cuestiones generales}

\begin{tabular}{|l|l|}
\hline 1 & ¿Cuál es la concepción de traducción adoptada por el libro didáctico? \\
\hline 2 & $\begin{array}{l}\text { ¿El libro didáctico hace referencia al uso de una perspectiva de traducción } \\
\text { en la enseñanza de idiomas? }\end{array}$ \\
\hline 3 & $\begin{array}{l}\text { ¿Qué abordaje de enseñanza de lengua extranjera embasa las actividades } \\
\text { de traducción del libro? }\end{array}$ \\
\hline
\end{tabular}

\section{EJE -02 -Tipos de actividades}

\begin{tabular}{|l|l|l|}
\hline 4 & \multicolumn{3}{|c|}{$\begin{array}{c}\text { ¿Qué tipo de ejercicios escritos de traducción son propuestos por el libro } \\
\text { didáctico? }\end{array}$} \\
\hline A & $($ ) & Organización morfosintáctica \\
\hline B & $($ ) & Secuencia de información en el texto. \\
\hline C & $($ ) & Completar espacios en blanco \\
\hline D & $($ ) & Redacción de textos \\
\hline E & $($ $)$ & Traducciones de texto \\
\hline F & $($ ) & Conjugación de verbos \\
\hline G & $($ ) & Preguntas abiertas. \\
\hline
\end{tabular}




\begin{tabular}{|l|l|l|}
\hline I & $(~)$ & Preguntas de respuestas múltiples \\
\hline J & $($ ) & Columnas \\
\hline K & $(\quad)$ & Crucigramas \\
\hline L & $($ $)$ & Correcciones \\
\hline M & $(\quad)$ & Resúmenes \\
\hline N & $(\quad)$ & Otros \\
\hline
\end{tabular}

EJE -03 - Modelo de Nord y el uso de textos auxiliares

5. ¿Los ejercicios de traducción explotan una tipología de textos auxiliares que puede servir de guía en el análisis del texto base y en la producción del texto meta en la práctica de la traducción pedagógica?

\begin{tabular}{|l|l|l|}
\hline 6. & \multicolumn{3}{|c|}{$\begin{array}{c}\text { ¿En los ejercicios planteados en los libros didácticos, cuáles informaciones } \\
\text { son proporcionadas para el proceso de traducción? }\end{array}$} \\
\hline A & $($ ) & Género textual (composición y funcionalidad) \\
\hline B & $($ ) & Lugar, tiempo y el porqué de la traducción. \\
\hline C & $($ ) & Funciones del texto en las culturas base y meta. \\
\hline D & $($ ) & Intención del autor \\
\hline E & $($ ) & Público receptor \\
\hline F & $($ ) & Temática y contenido \\
\hline G & $($ ) & Tipo de léxico utilizado, morfosintaxis y prosodia \\
\hline
\end{tabular}

\section{Análisis de los libros didácticos}

Con base en el guion, presentaremos enseguida el análisis y discusión de los datos observados de las actividades de traducción presentes en los libros de las tres colecciones del PNLD 2012. Luego, tras los resultados obtenidos propondremos una reformulación de dichas actividades con base en los principios funcionales de la teoría de Nord $(1996,1997,2012)$.

\section{El arte de leer español}

La colección está dividida en tres volúmenes y cada volumen presenta cuatro unidades. La apertura de cada unidad se da con una imagen que está relacionada de alguna manera a la temática que va a ser trabajada. Son explorados los más variados géneros textuales tanto en prosa como en poesía, así como de base informativa.

Con relación al lugar que ocupa la traducción en la colección, solo fue 
encontrada una actividad en el volumen 3, en la página 112, como muestra la imagen abajo:

Figura 1 - Actividad $1-$ v. 3

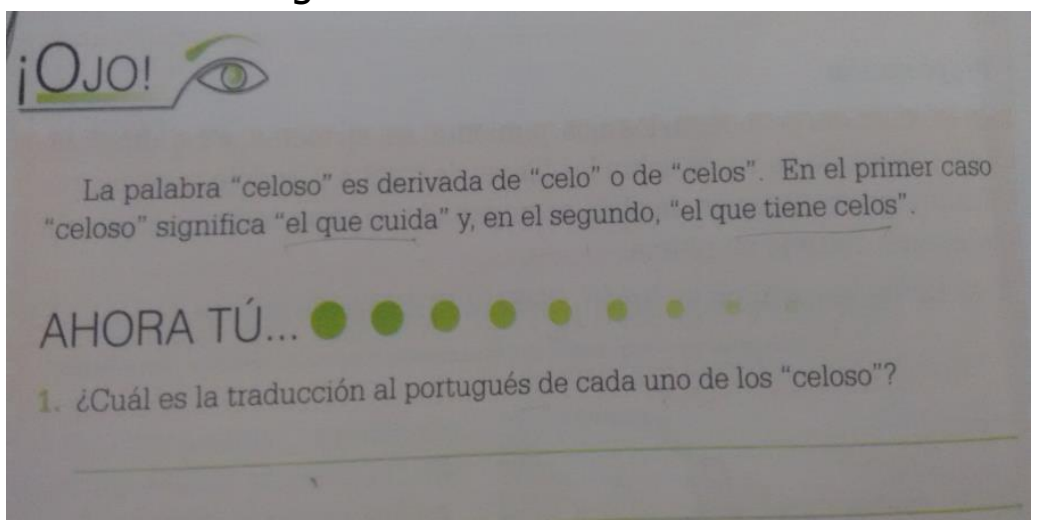

Fuente: Picanço y Villalba (2010, p. 112)

La imagen expone la poca atención que es dada a la traducción en el libro, principalmente, cómo es presentada en la actividad; se trabaja con una propuesta de abordaje directo y sin contextualización. Es solicitado al alumno que traduzca la palabra sin el recurso de textos auxiliares para el proceso de traducción, como propone Nord (2012). Tal abordaje, quita del alumno la autonomía de buscar el significado de las palabras y así, seguir con la traducción, en consiguiente, la falta de contextualización le impide mayores posibilidades de comprensión de significado del texto. En la teoría del scopo (en alemán Skopostheorie), que se fundamenta en la teoría de la acción, la traducción se determina por ser una interacción comunicativa realizada por medio de un texto. De ahí, la importancia de la utilización de textos en estas actividades de traducción. La actividad considera aspectos estructurales de la lengua con foco en la gramática, además no se considera el público meta que recibirá el mensaje. En el ejercicio es solicitado al alumno que haga la traducción de la palabra celoso que es derivada de celo o celos, que en nota dada anteriormente define que en el primer caso celoso significa "el que cuida" y, en el segundo "el que tiene celos". En este ejercicio, el libro trae una traducción directa de la palabra, excluyendo el alumno 
de un contexto comunicativo, en el que él infiriera el significado de la palabra a partir de su uso. Eso podría ser explotado a través del uso de textos auxiliares, como propone Nord (2012). Además, en la actividad, no son proporcionadas informaciones acerca del género, lugar, tiempo, funciones del texto base y meta, público receptor entre otros listados en el guion de análisis, elaborado a partir del marco teórico funcionalista.

Tras el análisis de dicha actividad, exponemos con base en la teoría funcional de la traducción y en los estudios de Nord (1997, 2005), la reformulación de la actividad analizada. Veamos los dos textos y la proposición de la actividad:

\section{CELOS DE TI}

\section{La migra}

Yo tengo celos de ti, es por tu amor tan profundo.

Tu enamorada de mi, sueños más bellos del mundo.

Yo espero con pasión, ayer tu corazón es la ilusión de mi vida.

Tú no tienes corazón, y en ellas la razón estar tan comprometida.

Ven que besos te daré, siempre recordaré con la ilusión de mi vida.

No me olvides nunca, quédate conmigo, que mi amor te busca,

$Y$ que al fin te encontró.

\section{POR UNA MUJER BONITA}

Pepe Aguilar

Por una mujer bonita

me estoy muriendo de celos

por una mujer bonita

traigo una penita en mi corazón

Yo sé que mucho me quiere yo sé que mucho la quiero, pero eso no me quita que ande una penita en mi corazón $Y$ tengo celos de todos 
los que a ti te miran pasar caminando

si se te quedan mirando

es cuando sufro por ti

Y es que tú estás tan bonita

bonita, bonita, como ya no hay nadie

por eso no soy culpable, por eso no soy culpable

Si tengo celos de ti

(Se repite todo)

Si tengo celos de ti

si tengo celos de ti

Cuadro 2- Propuesta de actividad 1

\begin{tabular}{|c|c|}
\hline NIVEL: & $3^{\circ}$ año de la enseñanza media. \\
\hline TIEMPO: & Aproximadamente 50 minutos. \\
\hline $\begin{array}{l}\text { ORIENTACIÓN } \\
\text { DIDÁCTICA: }\end{array}$ & $\begin{array}{l}\text { 1. "Considerar la heterogeneidad lingüística y cultural del } \\
\text { mundo hispánico en la enseñanza del español y estimular } \\
\text { esa reflexión." (OCNEM, 2006). }\end{array}$ \\
\hline $\begin{array}{l}\text { GÉNERO } \\
\text { TEXTUAL: }\end{array}$ & Canción. \\
\hline CONTENIDO & Léxico sobre el amor \\
\hline $\begin{array}{l}\text { DESCRIPCIÓN } \\
\text { DE LA } \\
\text { ACTIVIDAD: }\end{array}$ & $\begin{array}{l}\text { 1. Pasar el Videoclip de la canción "Celos de Ti" } \\
\text { (https://www.youtube.com/watch?v=O4HxyjxpBLI), } \\
\text { pedir que los alumnos lean la letra de la canción (VER EL } \\
\text { TEXTO A), luego, discutir la temática y el significado de } \\
\text { la palabra celos; } \\
\text { Pasar el Videoclip de la canción "Por una mujer bonita" } \\
\text { (https://www.youtube.com/watch?v=illasjYc1KQ), pedir } \\
\text { la lectura de la letra de la canción (VER EL TEXTO B), } \\
\text { luego, proponer una discusión del tema y el significado } \\
\text { de la palabra celos. } \\
\text { Contrastar el significado de la palabra celos en las dos } \\
\text { músicas, mostrando que las dos están adecuadas en sus } \\
\text { contextos. } \\
\text { Proponer la traducción de las canciones, al público } \\
\text { brasileño (jóvenes), y su publicación en la página de } \\
\text { Facebook: "traducción de canciones hispánicas a jóvenes } \\
\text { brasileños". }\end{array}$ \\
\hline $\begin{array}{l}\text { ORIENTACIONE } \\
\text { S PARA UNA } \\
\text { TRADUCCIÓN } \\
\text { FUNCIONAL: }\end{array}$ & $\begin{array}{l}\text { 1. El profesor puede pedir la traducción de las letras de } \\
\text { las dos canciones, a fin de explotar el léxico y el abordaje } \\
\text { del amor en las dos músicas en el par lingüístico español- } \\
\text { portugués. } \\
\text { 2. Antes de empezar la actividad, el profesor debe }\end{array}$ \\
\hline
\end{tabular}




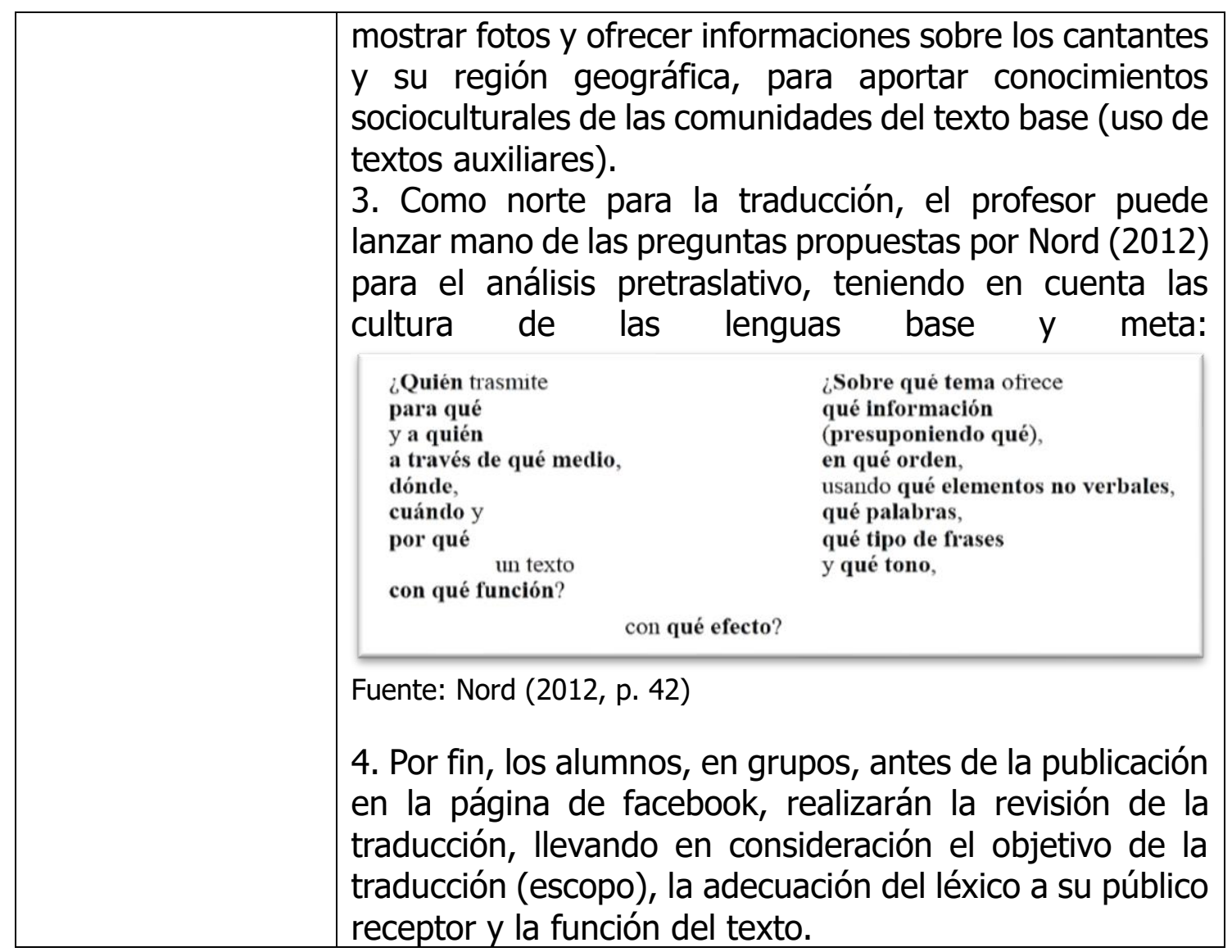

Fuente: Elaboración de los autores

Al pasar el videoclip de las canciones, antes de leer las letras de músicas, el profesor llamará la atención de los alumnos hacia la actividad y promoverá un ambiente más motivador, además de proponer la práctica auditiva de los estudiantes. Con la lectura de las letras de las músicas, se propone el reconocimiento del tema y del contexto, si son formales o informales. Para eso, el profesor puede fomentar la formulación de hipótesis por parte de los alumnos a fin de promover la reflexión lingüística y cultural, ya que las canciones expresan sentimientos universales, los cuales podemos aprovechar para acercar a la realidad cultural del alumno.

Por último, defendemos la idea de la inserción de elementos textuales dentro de la actividad, para que tal ejercicio no se vuelva para el alumno algo que sea irrealizable o difícil de realizar, sino que sea una situación comunicativa con un encargo y función establecidos, conforme propone Nord (2005). 


\section{Enlaces}

El libro está basado en los principios de las Orientaciones Curriculares Nacionales para la Enseñanza Media de Español en Brasil (OCEM - LE), explotando temas transversales, la diversidad lingüística y cultural de los países de habla española.

Las actividades en las unidades temáticas no presentan propuestas de traducción, aunque, en la sesión Español vs. Portugués, las autoras presentan un comparativo de las dos lenguas y proponen que el alumno identifique la similitud entre las lenguas.

Figura 2 - Actividad $02-v .1$

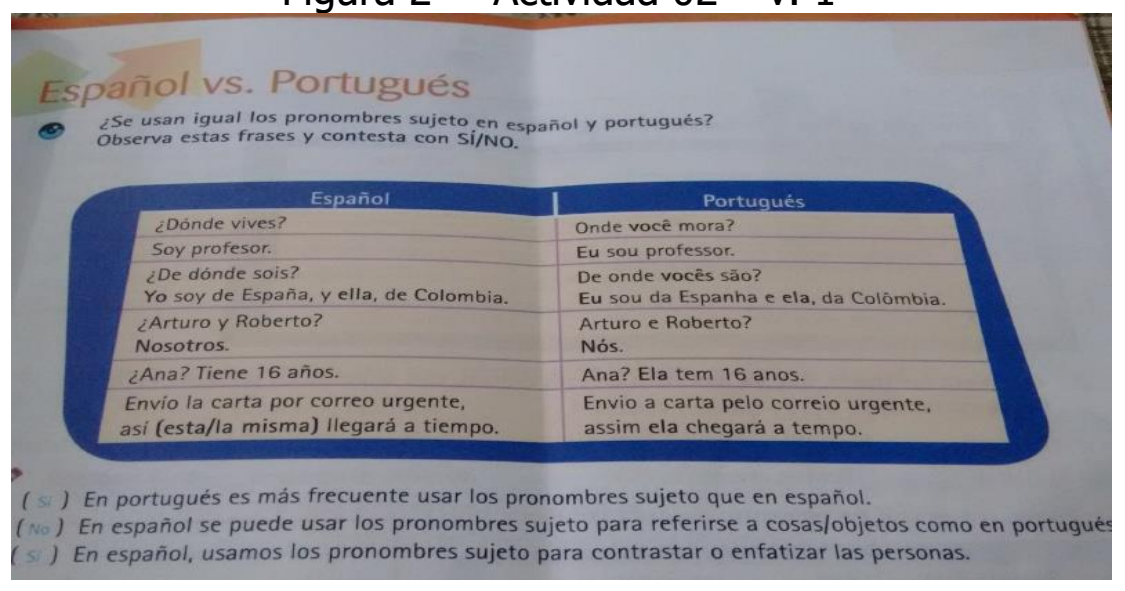

Fuente: Osman et al. (2010, p. 19)

Sería oportuno, ya que no está presente en ningún otro apartado, la inserción de la temática, que las autoras propusieran actividades de traducción en esa sesión posibilitando a los alumnos desarrollar mayor comprensión de la lengua por medio de la traducción. A ejemplo de esta colección, se percibe que los materiales didácticos no hacen uso de la traducción como recurso didáctico, y cuando lo hacen, se restringen a una traducción directa, desconsiderando el contexto de producción del texto de origen, de acuerdo con las investigaciones de Pontes y Francis (2014). Los manuales didácticos deberían considerar la traducción como una estrategia en las clases de ELE, y no limitarla a un concepto 
o a un área de estudio específica de los estudios de la traducción. Enfatizamos las ventajas de la utilización de la traducción en clases de LE, adaptadas por Mayoral (1998): a) es una actividad dirigida que mejora el trabajo con las cuatro destrezas; b) disminuye el peligro de la relación inequívoca para conferir importancia para el proceso de traducción y no al producto; c) se aprovecha del carácter de estudiantes monolingües para probar la comprensión oral y escrita, $y$, también, para analizar las similitudes y diferencias entre la lengua materna y la lengua extranjera.

\section{Síntesis}

El libro está organizado en tres volúmenes. Cada ejemplar está dividido en ocho unidades temáticas y por dos capítulos complementares que fueron añadidos uno en el medio del libro, tras la cuarta unidad y el otro al final, después de la octava unidad. El libro posee aún una tabla de conjugación de verbos y un glosario. Cada capítulo tiene, en su portada de apertura, una imagen y un pequeño texto que es una introducción al tema de la unidad.

La colección Síntesis adopta un abordaje comunicativo para la enseñanza de español. Sin embargo, se utiliza una concepción estructuralista del lenguaje, solicitando al alumno una traducción literal, sin considerar cualquier contexto, eso vemos en el volumen I del libro del primer año. Ya en el volumen II, en la página 78, el libro al presentar ejercicios de traducción, pide al alumno que haga la traducción de palabras, sin el auxilio de ningún texto, pues la actividad trae al inicio una foto y el siguiente título Hoy todos viajamos en cayucos..., luego solicita al alumno que, a partir de la foto conteste las preguntas. Al tratar de la foto, hace preguntas que solo serán contestadas con este auxilio. En otra, solicita que el alumno traduzca la palabra cayuco que se encuentra en el título del texto. Es esperado que el alumno diga que esta palabra significa barco solamente por la asociación con la foto. Eso hace que el alumno no tenga la oportunidad de tener conocimiento sobre las diversas variedades existentes en la lengua española y los distintos contextos de uso de la palabra, ya que el libro podría traer un texto 
en el que hubiera las distintas acepciones de la palabra y donde se usa cada una de ellas. Una vez más ponemos de relieve que la traducción puede contribuir para la enseñanza de idiomas, puesto que, a través de ella, podemos analizar los distintos matices de significados de una palabra o expresión, a partir de una situación comunicativa trasladada de una lengua/cultura a otra, teniendo en cuenta los elementos del cuadro propuesto por Nord (2012) (función, el público receptor, el lugar, el tiempo, el porqué de la traducción, etc). Presentamos enseguida una actividad del libro:

Figura 3 - Actividad $03-$ V.1

Figura 4 - Actividad $04-$ V.2

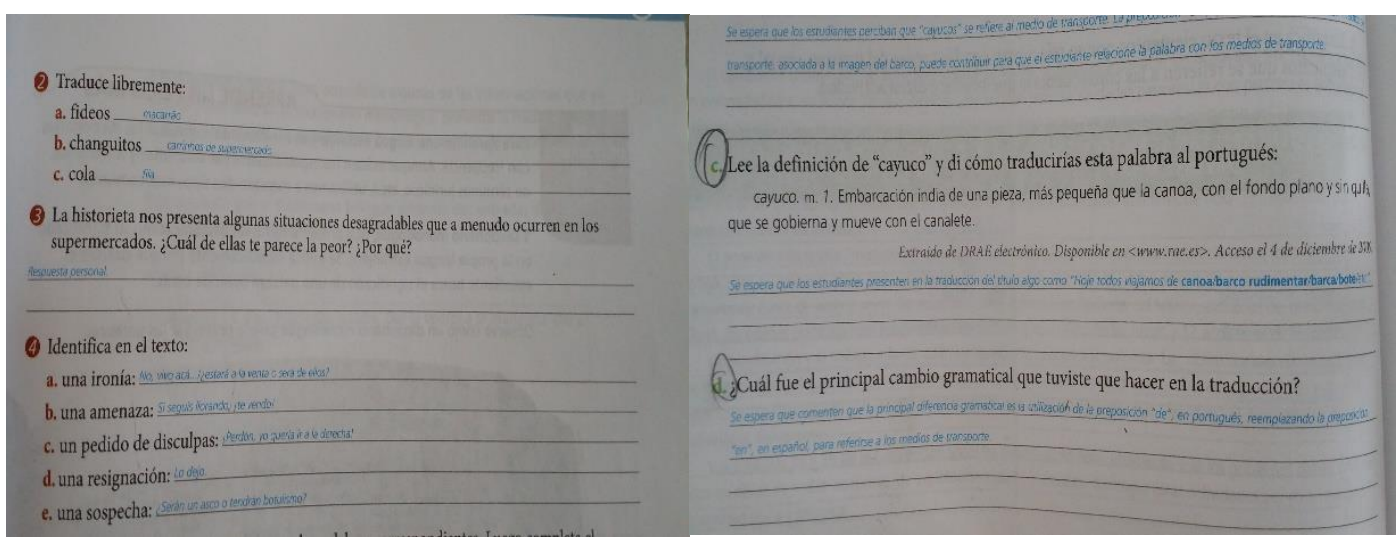

Fuente: Martin (2010, p.69)

Fuente: Martin (2010, p. 78)

El libro expone un abordaje de enseñanza de idiomas que inserta el alumno en el mundo de la lectura, oralidad y comprensión textual, a pesar de esto, quita el alumno de una actividad comunicativa de traducción, pues, al traer un abordaje estructural, excluye el alumno del universo comunicativo que la traducción proporciona.

El acto de traducir corrobora para la interacción comunicativa entre los miembros de comunidades con culturas distintas, creando un puente entre situaciones diferentes tanto en lo que se dice respecto a acciones verbales como no verbales, expectativas, conocimientos y puntos de vista que no ocultan al emisor y receptor de comunicarse de manera eficaz. Va más allá del hecho de 
traducir, es sobretodo posibilitar la comunicabilidad entre mundos distintos, según Reis y Vermeer (1996).

Los ejercicios de traducción que el libro trae se basan en un abordaje de enseñanza estructuralista del lenguaje, en que el alumno traduce palabras, descartando el contexto en el cual ellas deberían estar insertadas y eso puede generar dificultades para realizar la actividad. Según Nord (2005), el traductor, al encontrar dificultades para realizar el proceso de traducción, recurre a diversas clases de textos (géneros) para encontrar soluciones adecuadas. Nord (2005) elabora un estudio en que enumera varias soluciones a las que el traductor recurre al depararse con este tipo de problema. Veamos:

- personas (colegas, expertos de la disciplina, también personas ajenas a la traducción que pueden servir de «conejos de Indias» en ciertas situaciones);

- objetos (p. ej.: el aparato descrito en una documentación técnica)

- $y$, principalmente, textos.

Los dos primeros puntos se encajan mejor a traducciones profesionales, hechas por traductores en diversas reparticiones. Sin embargo, lo que nos interesa es el último punto: el traductor profesional recurre, principalmente, a textos para obtener más informaciones fácticas o lingüísticas. Llevando eso para las clases de idioma, al alumno realizar estas actividades, sería relevante que los libros aportasen textos que posibilitasen otros tipos de informaciones para la traducción de un texto.

Los ejercicios propuestos por el libro se basan en ejercicios de traducciones literales, donde el alumno no dispone de otro tipo de recurso para hacer la actividad. Al depararnos con un libro didáctico en la enseñanza de lenguas, encontramos a Tilio (2008), que señala cuatro características, que según él, define el libro texto.

(1) Están orientados por principios: principios básicos de conocimiento, según el modelo de teoría de lenguado dotado; (2) son metódicos: el 
conocimiento es dividido en elementos y clasificado, y el aprendizaje es secuencial y acumulativo; (3) son autoritarios: lo que el libro dice es siempre cierto; (4) son literales: deben ser seguidos literalmente y poseen formas y significados literales. (TILIO, 2008, p. 2, grifos del autor).$^{5}$

Sería oportuno, en este caso, adoptar lo que propone Nord (2012), en su trabajo con la utilización de textos auxiliares, es decir, para ayudar el alumno a desarrollar estas actividades en el intento de encontrar soluciones funcionales para los problemas de traducción, sobre todo en cuanto a las convenciones estilísticas o del género y al uso de los términos técnicos buscados. La autora propone una tipología de textos auxiliares que puede servir de guía, para el profesor y el alumno, en el análisis del texto base y la producción del texto meta. Cuanto a los ejercicios planteados en el libro no son proporcionadas informaciones acerca de género textual en lo que toca a su composición y funcionalidad. Tampoco, al modo, lugar y tiempo que ocupa la traducción en la actividad. El único objetivo del ejercicio es hacer que el alumno traduzca palabras, y eso proporciona a él una visión de que la traducción es solamente eso. Luego, lo que estos materiales producen permiten la creación de un pensamiento erróneo del profesor y del alumno con relación a la utilidad de la traducción en las clases de lenguas en lo que concierne a su práctica por parte del profesor, y metodología del docente por parte del alumno. Por fin, eso acaba por generar un cierto desinterés del alumno en lo que se refiere al aprendizaje de español.

Luego, tras el análisis, exponemos otra actividad que, también, propone cambio gramatical entre español y portugués, basada en la teoría funcionalista de la traducción. Para ello, veamos un trecho del cuento iDiles que no me maten! del escritor mexicano Juan Rulfo:

\footnotetext{
${ }^{5}(1)$ eles são guiados por princípios: Princípios básicos de conhecimento, de acordo com a teoria do único modelo fornecido; (2) são metódicos: o conhecimento é dividido em elementos e classificados, e aprender é seqüencial, cumulativo; (3) são autoritários: o que diz o livro é sempre verdadeiro; (4) são literais: literalmente devem ser seguidas e têm formas e significados literais. (TILIO, 2008, p. 2).
} 


\section{TEXTO C}

\section{Fragmento del cuento iDiles que no me maten!}

Entonces pensó que no tenía nada más que decir, que tendría que buscar la esperanza en algún otro lado. Dejó caer otra vez los brazos y entró en las primeras casas del pueblo en medio de aquellos cuatro hombres oscurecidos por el color negro de la noche.

-Mi coronel, aquí está el hombre.

Se habían detenido delante del boquete de la puerta. Él, con el sombrero en la mano, por respeto, esperando ver salir a alguien. Pero solo salió la voz:

-¿Cuál hombre? -preguntaron.

-El de Palo de Venado, mi coronel. El que usted nos mandó a traer.

-Pregúntale que si ha vivido alguna vez en Alima -volvió a decirla voz de allá adentro.

-iEy, tú! ¿Que si has habitado en Alima? -repitió la pregunta el sargento que estaba frente a él.

-Sí. Di leal coronel que de allá mismo soy. Y que allí he vivido hasta hace poco. -Pregúntale que si conoció a Guadalupe Terreros.

-Que dice que si conociste a Guadalupe Terreros. -¿A don Lupe? Sí. Dile que sí lo conocí. Ya murió.

Cuadro 3 - Propuesta de actividad 2

\begin{tabular}{|l|l|}
\hline NIVEL: & $2^{\circ}$ año de la enseñanza media. \\
\hline TIEMPO: & Aproximadamente 50 minutos. \\
\hline ORIENTACIÓN & $\begin{array}{l}\text { 1. "Comprender de qué forma determinada expresión } \\
\text { puede interpretarse en razón de aspectos sociales y/o } \\
\text { culturales." (PCEM, 2000). }\end{array}$ \\
\hline GÉNERO & Cuento \\
TEXTUAL: & $\begin{array}{l}\text { Pretérito Perfecto Simple (PPS) x Pretérito Perfecto } \\
\text { Compuesto (PPC) }\end{array}$ \\
\hline CONTENIDO & $\begin{array}{l}\text { 1. Pasar el cortometraje del cuento "Diles que no me } \\
\text { maten"(https://www.youtube.com/watch?v=qKoFQwCnoj } \\
\text { E), pedir que los alumnos lean el fragmento (VER EL } \\
\text { TEXTO C), luego, discutir la temática y el contenido; } \\
\text { DECTIVIDAD: } \\
\text { 2. Identificar los valores y los distintos contextos de uso } \\
\text { de los pretéritos (PPS y PPC); } \\
\text { 3. Analizar si el uso de los marcadores temporales está de } \\
\text { acuerdo con la norma patrón o si sufre variación en la } \\
\text { variedad mexicana. } \\
\text { 4. Proponer la traducción del fragmento, al público }\end{array}$ \\
\hline
\end{tabular}




\begin{tabular}{|l|l|}
\hline ORIENTACIONE & $\begin{array}{l}\text { brasileño (adulto), y su publicación en el blog: "traducción } \\
\text { de cuentos en Brasil". }\end{array}$ \\
\hline S PARA UNA profesor puede pedir la traducción del fragmento del \\
TRADUCCIÓN \\
FUNCIONAL: & $\begin{array}{l}\text { cuento, en grupos, a fin de explotar los usos de los } \\
\text { pretéritos (PPS y PPC) en el par lingüístico español- } \\
\text { portugués. } \\
\text { 2. El profesor debe ofrecer informaciones sobre el autor y } \\
\text { su país, para aportar conocimientos socioculturales de las } \\
\text { comunidades del texto base (uso de textos auxiliares). } \\
\text { 3. Antes de la traducción, el profesor debe proponer una } \\
\text { actividad en grupo para que los alumnos analicen los } \\
\text { siguientes aspectos de la propuesta de traducción: } \\
\text { (i) objetivo y motivo de la traducción; } \\
\text { (ii) función del texto en la cultura meta; } \\
\text { (iii) lugar, tiempo, medio; } \\
\text { (iv) público receptor. } \\
\text { 4. Analizar la traducción de los pretéritos de cada grupo } \\
\text { para el portugués brasileño, teniendo en cuenta la función } \\
\text { de cada forma y los matices de significado en la cultura } \\
\text { meta; } \\
\text { 5. Por fin, los alumnos, en grupos, antes de la publicación } \\
\text { en el blog, realizarán la revisión de la traducción, llevando } \\
\text { en consideración el objetivo de la traducción (escopo) y la } \\
\text { adecuación del texto a su público receptor. }\end{array}$ \\
\hline
\end{tabular}

Fuente: Elaboración de los autores

\section{Consideraciones finales}

En lo que toca a la inserción de la traducción en los libros, concluimos que las colecciones, al utilizar la traducción en los manuales, no visan el público meta que irá recibirla, o sea, las actividades no corresponden a los criterios que proponen la teoría funcional, puesto que considera que la traducción deba tener un público meta definido y que su proceso es intercultural, o sea, que se tiene en cuenta la cultura de quién pide y de quién recibe. Las actividades al explotar la traducción no tienen en cuenta aspectos de género, en lo que toca a su composición y funcionalidad, tampoco de lugar y tiempo. En lo que concierne a la traducción, no hay objetivo del porqué de la actividad, no hay recursos auxiliares, en este caso, el texto, para ayudar el alumno a realizar lo que propone 
el ejercicio, además no se considera el público meta.

Basado en lo expuesto, defendemos la utilización de la traducción en clases de español, en la perspectiva funcional. Reconociendo en este trayecto, su importancia para el aprendizaje de español. En lo que se refiere a su inserción en los manuales de enseñanza, sostenemos la idea de que los manuales al insertar la traducción deban llevar en cuenta lo que propone la teoría funcional de la traducción, pues al utilizar la aplicación de la teoría funcional, estarán considerando elementos lingüísticos y culturales del público meta.

Con este trabajo, buscamos contribuir para la producción y evaluación de los materiales didácticos de español. Además, de la utilización de la traducción como estrategia didáctica para la enseñanza de español como lengua extranjera. Por lo tanto, esperamos también que sirva de reflexión para la práctica docente y que posibilite el desarrollo de nuevos trabajos sobre la utilización de la traducción funcional en la enseñanza de lenguas extranjeras.

\section{Referencias}

AGUILAR, Pepe. Por una mujer bonita. Disponible en: <www.musica.com>. Acceso en: 06 jun. 2017.

BARROS, Adil de J. P.; LEHFELD, Neide A. S. Projeto de pesquisa: propostas metodológicas. 14. ed. Petrópolis: Vozes, 1990.

COAN, Márluce; PONTES, Valdecy de Oliveira. O. Variação modo-temporal em livros didáticos de língua espanhola e de língua portuguesa: uma análise comparativa. Linguagem \& Ensino, Pelotas, v. 16, n. 2, p. 363-392, jul./dic. 2013. Disponible en:

<http://www.rle.ucpel.tche.br/index.php/rle/article/view/887/686>. Acceso en: 20 jun. 2017.

LA MIGRA. Celos de ti. Disponible en:<www.musicafusion.com>. Acceso en: 6 jun. 2017.

LAIÑO, Maria José. A tradução pedagógica como estratégia à produção escrita em LE a partir do gênero publicidade. 2014. 234 f. Tesis (Doctorado en Estudios de la Traducción) - Centro de Comunicação e Expressão, Universidade Federal de Santa Catarina, Florianópolis, 2014. 
MARTIN, Ivan. Síntesis: curso de lengua española. São Paulo: Ática, 2011.

MAYORAL, Roberto. La traducción de la variación lingüística. 1998. Tesis (Doctorado en Estudios de la Traducción) - Universidade de Granada, Granada, 1998.

MILLÁS, Maria Leticia Nastari. Lidando com os falsos amigos: um estudo com base em análise de livros didáticos e em corpus linguístico. 2012. Disertación (Maestría en Estudios de la Traducción) - Universidade Federal de Santa Catarina, Florianópolis, 2012. Disponible en:

<https://repositorio.ufsc.br/handle/123456789/100713>. Acceso en: 20 jun. 2017.

NICOLAIDES, Christine; FERNANDES, Vera. Autonomia: critérios para escolha de material didático e suas implicações. En: LEFFA, Vilson J. (Org.). Produção de materiais de ensino: teoria e prática. 2. ed. Pelotas: EDUCAT, 2008.

NORD, Christiane. El error en la traducción: categorías y evaluación. En: HURTADO ALBIR, Amparo (Ed.). La enseñanza de la traducción. Castelló: Publicacions de la Universitat Jaume I, 1996. p. 91-107.

NORD, Christiane. Text analysis in translation: segunda edición completamente revisada. Amsterdam: Rodopi, 2005.

NORD, Christiane. Texto base-texto meta: un modelo funcional de análisis pretraslativo. Íkala: revista de lenguafe y cultura, Medellín, v. 18, n. 1, p. 101103, enero/abr. 2012. Disponible en:

<http://www.scielo.org.co/pdf/ikala/v18n1/v18n1a9.pdf>. Acceso en: 19 abr. 2017.

NORD, Christiane. Translating as a purposeful activity. Functionalist approaches explained. Manchester: St. Jerome, 1997.

OSMAN, Soraia et al. Enlaces: Español para jóvenes brasileños. 2. ed. São Paulo: Macmillan, 2010.

PICANÇO, Deise Cristina de Lima; VILLALBA, Terumi Koto Bonnet. El arte de leer español. Curitiba: Base Editorial, 2010.

PONTES, Valdecy de Oliveira; FRANCIS, Mariana. As variedades linguísticas nas atividades de tradução em livros didáticos de espanhol do PNLD 2011. Mutatis Mutandis, Medellín, v. 7, p. 83-99, 2014.

PONTES, Valdecy de Oliveira; PEREIRA, Livya Lea de Oliveira. A tradução a partir do modelo funcionalista de Christiane Nord: perspectivas para o ensino de línguas estrangeiras. Revista Tradterm, São Paulo, v. 14, p. 63-81, 2016. 
REISS, K.; VERMEER, H. J. Fundamentos para una teoría funcional de la traducción. Madrid: Akal, 1996.

SANTOS, Jorge Henrique Vieira. Livro didático: o grande vilão? São Paulo: Ed. Universitária, 1999. Disponible en:

<http://www.scribd.com/doc/16636704/Livro-didatico-heroi-ou-vilao>. Acceso en: 25 sept. 2016.

TILIO, Rogério. O papel do livro didático no ensino de língua estrangeira. Revista Eletrônica do Instituto de Humanidades, Rio de Janeiro, v. 7, n. 26, jul./sept. 2008. Disponible en:

<http://publicacoes.unigranrio.com.br/index.php/reihm/article/view/33>. Acceso en: 13 mayo 2017. 